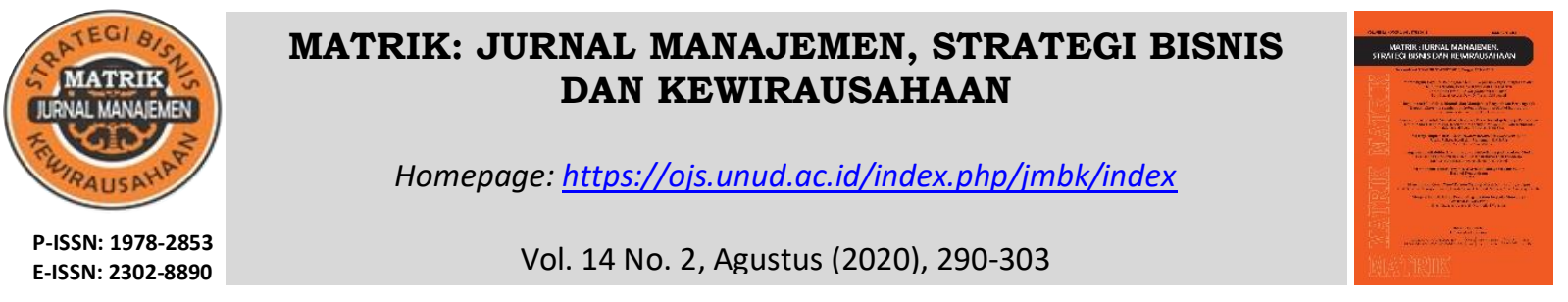

\title{
Turnover Intention Karyawan: Pengaruh Budaya Organisasi, Organizational Justice dan Kepuasan Kerja
}

\section{Noerchoidah}

Fakultas Ekonomi dan Bisnis Universitas PGRI Adi Buana Surabaya, Indonesia email: noerchoidah@unipasby.ac.id

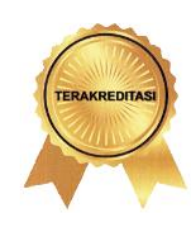

SINTA 2

DOI : https://doi.org/10.24843/MATRIK:JMBK.2020.v14.i02.p12

\begin{abstract}
ABSTRAK
Tujuan dari penelitian ini adalah untuk menganalisis penerapan konsep turnover intention pada karyawan hotel di Surabaya-Indonesia, dengan difokuskan pada peran dari konstruk kepuasan kerja sebagai variabel mediatornya. Riset ini juga bertujuan untuk menganalisis pengaruh variabel budaya organisasi dan organizational justice pada kepuasan kerja, serta menganalisis pengaruh kepuasan kerja terhadap turnover intention. Penelitian ini dilakukan pada 152 karyawan hotel di Surabaya dengan purposive sampling. Hasil penyebaran kuesioner diolah dengan teknik analisis Partial Least Square (PLS). Terdapat 7 hipotesis yang diajukan dalam penelitian ini, sebanyak 6 hipotesis yang terdukung, yaitu H1, H2, H4, H5, H6, dan H7. Sementara H3 tidak terdukung. Hasil penelitian ini mendukung social exchange theory. Adapun kesimpulan holistik penelitian ini bahwa model penelitian ini didukung secara empiris.
\end{abstract}

Kata Kunci: budaya organisasi, organizational justice, kepuasan kerja, turnover intention.

\section{Employee Turnover Intention: The Influence of Organizational Culture, Organizational Justice and Job Satisfaction}

\begin{abstract}
The purpose of this study is to analyze the application of the concept of turnover intention to hotel employees in Surabaya-Indonesia, with a focus on the role of the construct of job satisfaction as a mediating variable. This research also aims to analyze the influence of organizational culture variables and organizational justice on job satisfaction, and to analyze the effect of job satisfaction on turnover intention. This research was conducted on 152 hotel employees in Surabaya with purposive sampling. The results of distributing questionnaires were processed using Partial Least Square (PLS) analysis techniques. There are 7 hypotheses proposed in this study, 6 hypotheses are supported, namely H1, H2, H4, H5, H6, and H7. While H3 is not supported. The results of this study support social exchange theory. The holistic conclusion of this study is that this research model is supported empirically.
\end{abstract}

Keyword: organizational culture, organizational justice, job satisfaction, turnover intention

\section{PENDAHULUAN}

Surabaya merupakan pusat bisnis dan perdagangan yang mengalami perkembangan pesat sehingga banyak pelaku bisnis yang menjalankan bisnis di Surabaya dan sebagai pusat kuliner, properti, maupun perhotelan. Banyak hotel yang dapat dipilih sebagai tempat peristirahatan. Hotel di Surabaya mengalami pertumbuhan yang pesat sekali. Berdasarkan pada hasil wawancara dengan Ketua PHRI bahwa jumlah hotel di Surabaya setiap tahunnya mengalami pertumbuhan $7.8 \%$.

Persaingan yang kompetitif menuntut peran sumber daya manusia untuk memiliki keunggulan bersaing. Bagi perusahaan mengelola sumber daya manusia menjadi faktor penting 
untuk meningkatkan daya saing dalam keberhasilan perhotelan. Sumber daya manusia merupakan aset berharga dan berperan sentral dalam sektor jasa untuk mencapai tujuan organisasi. Pengelolaan kayawan untuk menjaga kepuasaan kerja karyawan terhadap pekerjaan yang menjadi tanggung jawabnya dan meningkatkan loyalitas karyawan terhadap perusahaan. Karyawan yang memiliki loyalitas tinggi untuk tetap berada di perusahaan merupakan bagian penting dalam pengelolaan sumber daya manusia.

Pada sektor perhotelan ditemukan masalah yang mendasar terjadi pada tingkat turnover karyawan yang tinggi yang dapat mempengaruhi kualitas layanan (Mok dan Luk, 1995). Turnover merupakan wujud nyata dari turnover intention yang memberikan dampak bagi perusahaan. Menurut Foley (1996) bahwa turnover sektor perhotelan lebih besar 34.7\% dibandingkan pada sektor manufacturing. Tingkat turnover yang tinggi (melebihi 10\%) merupakan salah satu ukuran yang mengindikasi adanya masalah yang terjadi di perhotelan berkaitan dengan hilangnya modal sosial, berkurangnya semangat kerja, biaya pelatihan, rekruitmen, dan memori perusahaan yang menyertai kepergian personel. Turnover intention merupakan suatu keadaan dimana pekerjamemiliki niat atau kecenderungan yang dilakukan secara sadar untuk mencari pekerjaan lain sebagai alternatif di organisasi yang berbeda (Abdullah dan Musa, 2011). Pengaruh turnover intentiondiantara karyawan sangat mengkhawatirkan bagi perusahaan saat ini.Perputaran karyawan dalam jumlah yang besar di perusahaan perlu mendapat perhatian serius dan perlu digali alasan karyawan berhenti (Swasto, 2011). Sejumlah penelitian menemukanbahwa turnover intentionkaryawan dipengaruhi oleh budaya organisasi, kepuasan kerja, komitmen organisasional (MacIntosh \& Doherty, 2010), dan organizational justice (MacIntosh dan Doherty, 2010; Suifan, T. S., Diab, H., dan Abdallah, 2017).

Menurut social exchange theory (Blau, 1964) bahwa sebuah organisasi dapat melakukan tindakan positif terhadap karyawan dengan harapan bahwa inisiatif tersebut akan mendapat balasan dalam hal kesetiaan terhadap organisasi, sehingga dapat mengurangi turnover intention. Dalam hal ini, karyawan akan mengevaluasi perlakuan yang diterima dari organisasi untuk menentukan apakah akan melanjutkan hubungan atau tidak melanjutkan. Social exchange melibatkan serangkaian interaksi yang saling bergantung yang melibatkan kewajiban antara dua pihak.

Budaya organisasi bagi perusahaan sangat penting yang dapat mempengaruhi sikap dan perilaku individu serta kinerja perusahaan. Budaya organisasi bertindak sebagai sistem kontrol sosial dan dapat mempengaruhi sikap dan perilaku karyawan melalui nilai-nilai dan kepercayaan yang beroperasi di perusahaan.Budaya organisasi telah terbukti memiliki pengaruh signifikan dan positif pada kepuasan kerja karyawan Troena, dan Setiawan, 2012). Budaya organisasi dan turnover intention memiliki pengaruh signifikan dan negatif (Yeun dan Han, 2016; Kessler, 2014; Idiegbeyan-Ose, Opeke, Nwokeoma, dan Osinulu, 2018; Bosomtwe dan Obeng, 2018). Sementara itu, Tumbelaka, Habsji, dan Nimran (2016) menemukan bahwa budaya organisasi terbukti tidak signifikan dan negatif secara langsung mempengaruhi turnover intention. Penelitian lain olehDwivedi, Kaushik, dan Luxmi (2013) menemukan pengaruh signifikan dan positif antara budaya organisasi dan turnover intention. Berdasarkan inkonsistensi hasil dari penelitian sebelumnya merupakan research gap sehingga menarik untuk dilakukan penelitian selanjutnya.

Organizational justice dan konsekuensinya perlu dipahami dengan baik oleh para pimpinan di industri perhotelan dalam mengembangkan kebijakan dan prosedur yang dilembagakan di tempat kerja. Organizational justice sangat penting dalam membentuk sikap dan perilaku karyawan baik atau buruk yang dapat berdampak positif atau negatif pada kinerja karyawan di perusahaan (Al-Zu'bi, 2010; Robbin dan Judge, 2019:144). Organizational justice 
sebagai perlakuan keadilan yang dipersepsikan karyawan dari para pimpinan dan pembuat keputusan di tempat kerja. Menurut Robbin dan Judge (2019:145) organizational justice terdiri dari distributive justice, procedural justice, dan interctional justice. Distributive justice merupakan keadilan yang dirasakan dari kewajaran hasil yang diterima. Menurut Adams (1965) distributive justice adalah kewajaran hasil yang diterima karyawan berdasarkan equity theory. Equity theory merupakan teori yang secara kognitif menjelaskan apa yang akan dilakukan seseorang ketika seseorang dihadapkan pada situasi ketidakadilan dalam pekerjaannya melalui ukuran persepsi terhadap rasio hasil yang diterimanya (output) dibandingkan dengan masukan yang telah diberikannya (input) berdasarkan keadilan dalam social exchange (Adams, 1965; Zhang, Lepine, Buckman, dan Wei, 2014).Karyawan akan membandingkan antara rasio output atau input dengan rekannya. Jika rasio yang diterima sama dengan rekannya maka dikatakan distributive justice tercapai di dalam perusahaan (Robbin dan Judge, 2019: 145). Procedural justice merupakan keadilan yang dirasakan dari prosedur yang digunakan untuk pengambilan keputusan (Wang, Liao, Xia, dan Chang, 2010; Yean dan Yusof, 2016). Interactional justice adalah keadaan dimana pihak berwenang memperlakukan bawahannya selama berlakunya prosedur organisasi berkaitan dengan interpersonal dan informasional (Karkoulian, Assaker, dan Hallak, 2016).

Kepuasan kerja didefinisikan sebagai suatu perasaan positif tentang pekerjaan yang dihasilkan dari suatu evaluasi dari karakteristik-karateristiknya (Robbin dan Judge, 2019:46). Karyawan dengan tingkat kepuasan kerja yang tinggi memiliki perasaan yang positif mengenai pekerjaannya, sedangkan seseorang dengan level yang rendah memiliki perasaan negatif. Ketidakpuasan kerja karyawan akan mengarah pada perilaku meninggalkan perusahaan termasuk mencari sebuah posisi yang baru serta pengunduran diri (Regts dan Molleman, 2013).

Penelitian ini dilakukan untuk menguji pengaruh budaya organisasi dan organizational justiceterhadap turnover intention karyawan hotel baik secara langsung maupuntidak lagsung melalui kepuasan kerja sebagai mediasi.

Budaya organisasi merupakan suatu sistem berbagi arti yang dilakukan para anggota yang membedakan suatu organisasi dari organisasi lainnya (Robbin dan Judge, 2019:355). Budaya organisasi mengacu pada sistem nilai, kepercayaan dan perilaku yang dibagi di antara karyawan (Cui dan $\mathrm{Hu}, 2012$ ). Budaya organisasi mempengaruhi kepuasan kerja karyawan, dengan budaya yang lebih kuat akan memiliki dampak yang tinggi pada kepuasan kerja karyawan, sebaliknya budaya organisasi yang rendah akan memiliki dampak yang rendah pada kepuasan kerja karyawan (Robbin dan Judge, 2019:379). Budaya organisasi telah terbukti berperan penting dalam kepuasan kerja (Belias, Koustelios, Vairaktarakis, dan Sdrolias, 2015; Noerchoidah dan Harryono, 2019)

Hasil sejumlah penelitian mengungkapkan hubungan positif antara budaya organisasi dan kepuasan kerja (Mansor dan Tayib, 2010; Henry Syauta et al., 2012; Mohamed, Shurbagi, dan Zahari, 2012). Berdasarkan pada penelitian empirik di atas, penelitian ini memformulasikan hipotesis berikut:

$\mathrm{H}_{1}$ : Budaya organisasi berpengaruh signifikan terhadap kepuasan kerja karyawan.

Ketidakpuasan terjadi ketika karyawan memiliki pemikiran keluar dari perusahaan untuk mendapatkan pekerjaan lain yang lebih baik dan mampu memberikan kepuasan kerja yang lebih baik (Richardson, Yang, Vandenberg, DeJoy, dan Wilson, 2008). Mbah dan Ikemefuna (2012) menemukan bahwa semakin besar kepuasan kerja karyawan maka semakin rendah turnover intention, sebaliknya apabila kepuasan kerja rendah maka turnover intention menjadi tinggi. Hal ini berarti karyawan yang merasakan puas atas pekerjaan akan memiliki sikap positif terhadap pekerjaannya dan tidak ada keinginan untuk keluar dari perusahaan.

Kepuasan kerja terhadap turnover intention memiliki hubungan negatif, dimana semakin kepuasan kerja meningkat maka turnover intention menurun sehingga kinerja 
perusahaan dapat ditingkatkan. Adanya hubungan negatif kepuasan kerja terhadap turnover intention ditemukan dalam penelitian Abela dan Debono, 2019; MacIntosh dan Doherty, 2010; Emami, Moradi, Idrus, dan Almutairi, 2012. Kepuasan kerja dan turnover intention memiliki korelasi yang kuat, dimana kepuasan kerja sangat mempengaruhi turnover intention. Berdasarkan uraian tersebut, maka dapat dirumuskan hipotesis sebagai berikut:

$\mathrm{H}_{2}$ : Kepuasan kerja berpengaruh signifikan terhadap turnover intention karyawan.

Budaya merupakan identitas suatu organisasi dan mencerminkan nilai-nilai fundamental yang penting bagi organisasi tersebut. Budaya organisasi memiliki peranan untuk menciptakan perbedaan antara salah satu organisasi dengan organisasi lainnya, sebagai identitas bagi para anggota organisasi (Robbin dan Judge, 2019:359). Budaya merupakan perekat sosial yang membantu mengikat organisasi secara bersama-sama dengan menyediakan standar bagi apa yang seharusnya dikatakan dan dilakukan oleh para karyawan.

Budaya organisasi menjadi faktor penting dalam menentukan kecocokan antara karyawan sebagai individu individu cocok dengan perusahaan. Karyawan yang cocok dengan budaya organisasi akan memiliki keinginan turnover intention kerja yang lebih kecil ke perusahaan lain. Budaya organisasi yang memberikan tantangan bagi ketidakhadiran karyawan yang berkurang dan turnover intentiondari pekerjaan, jabatan, dan organisasi (Dwivedi et al., 2013).

Beberapa hasil penelitian sebelumnya menemukan bahwa budaya organisasi signifikan dan negatif mempengaruhi turnover intention karyawan (Jacobs dan Roodt, 2011; Dwivedi et al., 2013; Yeun dan Han, 2016; Bosomtwe dan Obeng, 2018). Berdasarkan uraian tersebut, maka dapat dirumuskan hipotesis sebagai berikut:

$\mathrm{H}_{3}$ : Budaya organisasi berpengaruh signifikan terhadap turnover intentionkaryawan

Organizational justice di tempat kerja yang dirasakan karyawan pada tingkatan tinggi akan mempengaruhi perasaan puas atas pekerjaan yang dilakukan. Sebaliknya jika organizational justice di tempat kerja berada pada tingkatan rendah dapat menimbulkan ketidakpuasan karyawan (Abekah-Nkrumah dan Atinga, 2013; (Noerchoidah, Eliyana, dan Christiananta, 2020)

Dijelaskan oleh Robbin dan Judge (2019: 49) kepuasan kerja didefinisikan sebagai perasaan positif terhadap pekerjaan yang dihasilkan dari karakteristik-karakteristiknya. Kepuasan kerja melibatkan perasaan karyawan terhadap pekerjaannya yang dapat membentuk perasaan positif atau negatif tentang situasi pekerjaannya. Oleh karenanya, memperhatikan kepuasan kerja sangat penting bagi perusahaan dan sebagai penentu potensial dari hasil di tempat kerja (Barakat, Isabella, dan Boaventura, 2016).

Beberapa penelitian telah mengkonfirmasi pengaruh positif organizational justice terhadap kepuasan kerja dalam memaksimalkan hasil kerja karyawan (Al-Zu'bi, 2010; Nadiri dan Tanova, 2010; Imran, 2015; Suifan, Diab, dan Abdallah, 2017; Suifan, 2019). Berdasarkan uraian tersebut, maka dapat dirumuskan hipotesis sebagai berikut:

$\mathrm{H}_{4}$ : Organizational justice berpengaruh signifikan terhadap kepuasan kerja karyawan.

Organizational justice berkaitan dengan persepsi karyawan mengenai perlakuan adil yang diterima dari organisasinya. Apabila karyawan merasakan adanya ketidakadilan di tempat kerja dapat memicu penurunan kinerja, tingginya tingkat kemangkiran, dan turnover intention (Bernerth dan Walker, 2012; Kwon Choi, Koo Moon, Ko, dan Min Kim, 2014). Semakin tinggi tingkat organizational justice yang dirasakan karyawan maka semakin rendah turnover intention. 
Turnover intention adalah keinginan individu secara sukarela untuk meningggalkan perusahaan karena beberapa alasan, sehingga secara negatif merugikan bagi perusahaan. Tingginya turnover intention menyebabkan adanya kekuatiran bagi perusahaan bahwa karyawan yang memiliki kemampuan dan ketrampilan yang lebih baik pergi meningggalkan perusahaan sedangkan yang tetap tinggal di perusahaan adalah karyawan yang tidak menemukan pekerjaan lain. Hal ini dapat mempengaruhi tingkat layanan yang diberikan kepada pelanggan karena hilangnya semangat dari karyawan yang masih memilih untuk tetap di perusahaan (Kaur, 2014).

Beberapa penelitian telah mengungkapkan pengaruh yang signifikan dan negatif antara organizational justice dan turnover intention (Nadiri dan Tanova, 2010; Suifan, Diab, dan Abdallah, 2017; Arif, 2018). Berdasarkan uraian tersebut, maka dapat dirumuskan hipotesis sebagai berikut:

$\mathrm{H}_{5}$ : Organizational justice berpengaruh signifikan terhadap turnover intention karyawan.

Turnover intention sebagai reaksi terhadap hasil yang dirasakan tidak memuaskan dari organisasi. Penelitian telah menunjukkan bahwa organizational justice mempengaruhi sikap dan perilaku di tempat kerja. Penelitian sebelumnya menunjukkan bahwa organizational justice memiliki pengaruh pada sikap dan perilaku karyawan di tempat kerja seperti kepuasan kerja dan akhirnya pada turnover intention. Oleh karenanya, kepuasan kerja sangat penting dalam memediasi dalam hubungan organizational justice dan turnover intention (Suifan, Diab, dan Abdallah, 2017; Kuntardina, 2017).

Parker dan Kohlmeyer (2005) menyatakan bahwa hubungan antara organizational justice dan turnover intention harus diteliti melalui faktor mediasi kepuasan kerja.

Penelitian sebelumnya menemukan bahwa budaya memiliki dampak pada turnover intention, dan kepuasan kerja sebagai mediator pada turnover intention secara statistik menunjukkan signifikan (Egan, Yang, dan Bartlett, 2004; Park dan Kim, 2009).

Berdasarkan uraian tersebut, maka dapat dirumuskan dua hipotesis sebagai berikut:

$\mathrm{H}_{6}$ : Kepuasan kerja signifikan memediasi hubungan antara budaya organisasi dan turnover intention karyawan

$\mathrm{H}_{7}$ : Kepuasan kerja signifikan memediasi hubungan antara organizational justice dan turnover intention karyawan.

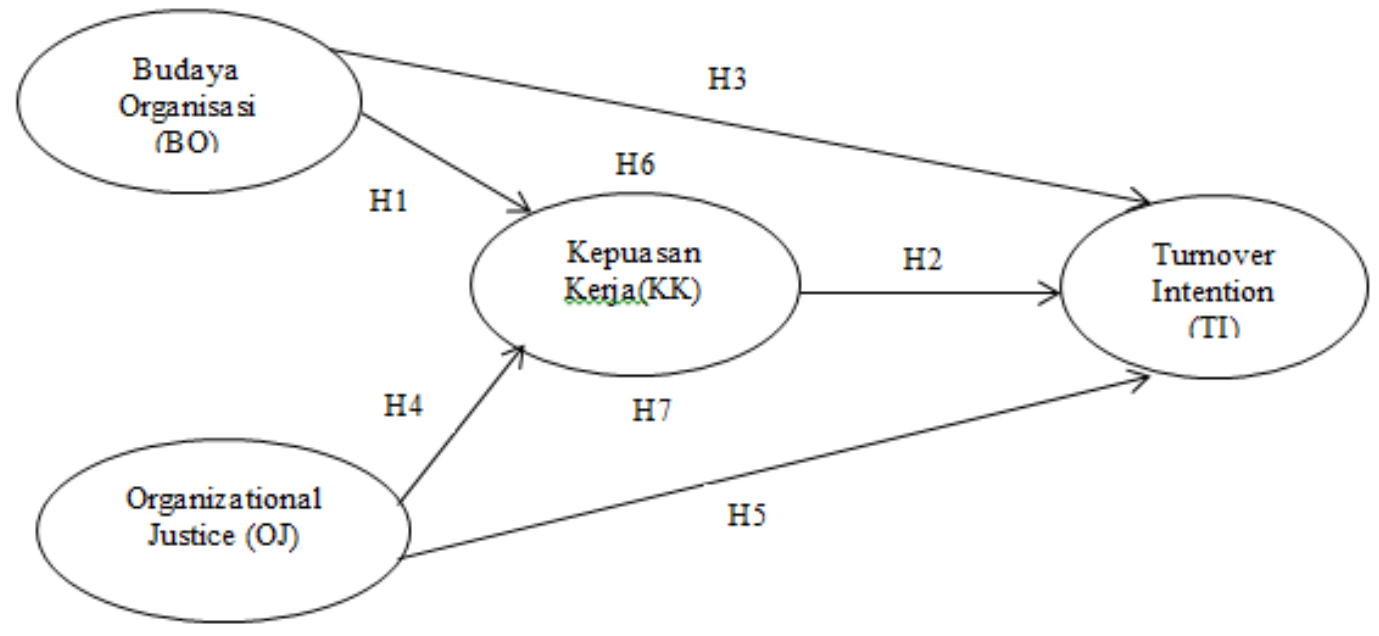

Gambar 1. Model Konseptual Penelitian

Sumber: Data Primer, diolah 


\section{METODE PENELITIAN}

Penelitian ini dilakukan pada karyawan hotel di Surabaya, Jawa Timur. Semua karyawan yang bekerja pada hotel di Surabaya adalah target populasi. Instrumen pengumpulan data penelitian menggunakan kuesioner. Skala pengukuran untuk mengukur respon responden menggunakan scala Likert 5 point, yaitu: $1=$ sangattidak setuju, $2=$ tidak setuju, $3=$ netral, $4=$ setuju, 5 = sangat setuju. Unit sampel yang digunakan dalam penelitian ini, yakni karyawan yang telah bekerja minimal 1 tahun. Adapun metode pemilihan sampel yang digunakan dalam penelitian ini adalah non probability sampling yaitu purposive sampling.

Menurut Ghozali (2017: 64)bahwa penentuan jumlah sampel dapat ditentukan dengan 5-10 parameter kali banyaknya indikator. Berdasarkan pendapat tersebut, penelitian ini menggunakan 20 indikator sehingga minimal sampel sebanyak 20 x $5=100$ responden. Sampel yang digunakan dalam penelitian ini sebanyak 152 responden dengan maksud semakin besar jumlah responden yang digunakan akan semakin akurat. Teknik analisis menggunakan Partial Least Square (PLS).

Penelitian ini menggunakan alat ukur dari MacIntosh dan Doherty (2010) untuk mengukur budaya organisasi dengan 3 item. Contoh item "Apabila diberikan tugas saya berusaha menyelesaikan dengan tepat waktu". Kepuasan kerja diukur dengan menggunakan 4 item dari Tzeng (2002).Contoh item "Secara keseluruhan saya puas dengan pekerjaan saya".Turnover intention menggunakan alat ukur dari Koslowsky, Weisberg, Yaniv, dan Zaitman (2012) dengan 4 item. Contoh item "Saya sering berpikir untuk keluar dari perusahaan". Organizational justice diukur dengan distributive justice, procedural justice, interactional justice dari Al-Zu'bi (2010) menggunakan 9 item. Contoh item distributive justice "Saya merasakan beban kerja telah sesuai dengan reward yang saya terima". Contoh item procedural justice "Saya merasa perusahaan mengijinkan karyawan untuk mengekspresikan pendapat sebelum keputusan ditetapkan". Contoh item interactional justice, yaitu "Ketika keputusan dibuat tentang pekerjaan saya, pimpinan memperlakukan saya dengan sopan".

\section{HASIL DAN PEMBAHASAN}

Asumsi linearitas untuk menjelaskan hubungan antara variabel. Model linear signifikan apabila $\mathrm{p}<0.05$ berarti hubungan antar variabel dapat dijelaskan menggunakan model linier. Apabila $\mathrm{p}>0.05$ maka model linier tidak signifikan. Hasil uji disajikan sebagai berikut:

Tabel 1. Uji Asumsi Linieritas

\begin{tabular}{ccccc}
\hline \multicolumn{2}{c}{ Hubungan Variabel } & Uji Model Linier & $\mathrm{p}$ & Keterangan \\
\hline X1 & Y1 & Model linier signifikan & 0.000 & Linier \\
X1 & Y2 & Model linier signifikan & 0.000 & Linier \\
X2 & Y1 & Model linier signifikan & 0.000 & Linier \\
X2 & Y2 & Model linier signifikan & 0.000 & Linier \\
Y1 & Y2 & Model linier signifikan & 0.000 & Linier \\
\hline
\end{tabular}

Sumber: Data primer, diolah

Setelah dilakukan uji asumsi linieritas seperti yang tampak pada Tabel 1, menunjukkan bahwa secara keseluruhan hubungan antar variabel linier.

Pada pengujian validitas konvergen, nilai outer loading factor yang diharapkan adalah lebih besar dari 0,7 (Wijaya, 2019). Hal ini mengindikasikan terpenuhinya uji validitas konvergen, seperti yang ditunjukkan pada Tabel 2. 


\section{Average Variance Extracted (AVE)}

Nilai AVE digunakan untuk mengukur banyaknya varians yang dapat ditangkap oleh konstruknya dibandingkan dengan variansi yang ditimbulkan oleh kesalahan pengukuran. Nilai AVE harus lebih besar (>0.5). Hasil pengujian validitas konvergen yang didasarkan AVE menunjukkan bahwa keseluruhan konstruk dalam penelitian ini valid, seperti yang ditunjukkan pada Tabel 3.

Tabel 2. Hasil Uji Validitas Konvergen

\begin{tabular}{cccc}
\hline Variabel & Indikator & Outer Loading & Keterangan \\
\hline Budaya Organisasi (X1) & X1.1 & 0.870 & Valid \\
& X1.2 & 0.798 & Valid \\
Organizational Justice (X2) & X1.3 & 0.885 & Valid \\
& X2.1 & 0.770 & Valid \\
& X2.3 & 0.758 & Valid \\
X2.4 & 0.895 & Valid \\
& X2.5 & 0.738 & Valid \\
Xepuasan Kerja (Y1) & X2.7 & 0.782 & Valid \\
& X2.8 & 0.842 & Valid \\
& X2.9 & 0.723 & Valid \\
& Y1.1 & 0.711 & Valid \\
Intention turnover (Y2) & Y1.2 & 0.704 & Valid \\
& Y1.3 & 0.735 & Valid \\
& Y1.4 & 0.732 & Valid \\
& Y2.1 & 0.708 & Valid \\
& Y2.2 & 0.784 & Valid \\
& Y2.3 & 0.769 & Valid \\
& Y2.4 & 0.744 & Valid \\
& & 0.704 & Valid \\
& & 0.705 & Valid \\
\hline
\end{tabular}

Sumber: Data primer, diolah

Tabel 3. Hasil Uji AVE

\begin{tabular}{lcc}
\hline Variabel & AVE & Keterangan \\
\hline Budaya Organisasi & 0.789 & Valid \\
Organizational Justice & 0.619 & Valid \\
Kepuasan Kerja & 0.787 & Valid \\
Intention Turnover & 0.623 & Valid \\
\hline
\end{tabular}

Sumber: Data primer, diolah

\section{Uji Reliabilitas}

Uji reliabilitas ini menunjukkan konsistensi nilai internal yaitu nilai composite reliability yang tinggi menunjukan nilai konsistensi dari masing-masing indikator dalam mengukur konstruknya. Nilai CR > 0.7 dan nilai cronbach's alpha> 0.7. Hasil pengujian reliabel yang didasarkan pada Composite reliability test dan cronbach alpha adalah reliabel, seperti ditunjukkan pada Tabel 4.

\section{Goodness of Fit}

Berdasarkan hasil pengolahan data didapatkan sejumlah luaran yang dapat digunakan untuk menilai fit atau tidaknya model penelitian. 
Tabel 4. Uji Composite Reliability

\begin{tabular}{lccc}
\hline Variabel & $\begin{array}{c}\text { Composite Reliability } \\
(>0.7)\end{array}$ & $\begin{array}{c}\text { Cronbach's Alpha } \\
(>0.7)\end{array}$ & Keterangan \\
\hline Budaya Organisasi & 0.848 & 0.724 & Reliabel \\
Organizational Justice & 0.829 & 0.832 & Reliabel \\
Kepuasan kerja & 0.805 & 0.745 & Reliabel \\
Intention Turnover & 0.796 & 0.819 & Reliabel \\
\hline
\end{tabular}

Sumber: Data primer, diolah

Cronbach Alpha, semuanya memberikan nilai yang memenuhi kiriteria goodness of fit dari model. Dengan demikian dapat disimpulkan bahwa model keseluruhan dapat dinyatakan sudah baik seperti pada Tabel 5.

Tabel 5.Goodness of Fit of Structural Model(Inner Model)

\begin{tabular}{lcccc}
\hline \multicolumn{1}{c}{ Variabel } & $\begin{array}{c}\text { Composite } \\
\text { Reliability } \\
(>0.7)\end{array}$ & $\begin{array}{c}\text { Cronbach's Alpha } \\
(>0.7)\end{array}$ & $\begin{array}{c}\text { AVE } \\
(>0.5)\end{array}$ & Keterangan \\
\hline Budaya Organisasi & 0.848 & 0.724 & 0.789 & Baik \\
Organizational Justice & 0.829 & 0.832 & 0.619 & Baik \\
Kepuasan kerja & 0.805 & 0.745 & 0.787 & Baik \\
Intention Turnover & 0.796 & 0.819 & 0.623 & Baik \\
\hline \multicolumn{2}{l}{ Sumber: Data primer, diolah } & & &
\end{tabular}

Pengujian hipotesis ini menggunakan nilai t-tabel yaitu dengan nilai sebesar 1.96. Tabel 6 menyajikan hubungan kausalitas pengaruh langsung dengan uji t statistik pada pengaruh masing-masing jalur secara parsial. Hasil menunjukkan sebanyak 4 hipotesis yang terdukung, yaitu H1, H2, H4, dan H5, sementara itu hipotesis tidak terdukung adalah H3. Sementara pada Tabel 7 menyajikan hasil mediasi kepuasan kerja, menunjukkan bahwa H6 dan H7 terdukung.

Tabel 6. Hasil Pengujian Hipotesis Pengaruh Langsung

\begin{tabular}{|c|c|c|c|c|c|}
\hline Variabel Independen & Variabel Dependen & $\begin{array}{c}\text { Path } \\
\text { Coefficient }\end{array}$ & $\mathrm{p}$-value & $\mathrm{t}$ hitung & Keterangan \\
\hline $\begin{array}{l}\text { Budaya Organisasi } \\
\text { (BO) }\end{array}$ & $\begin{array}{l}\text { Kepuasan Kerja } \\
\text { (KK) }\end{array}$ & 0.358 & 0.000 & 7.332 & Signifikan \\
\hline $\begin{array}{l}\text { Kepuasan Kerja } \\
(\mathrm{KK})\end{array}$ & $\begin{array}{l}\text { Turnover } \\
\text { Intention (TI) }\end{array}$ & -0.224 & 0.033 & 5.994 & Signifikan \\
\hline $\begin{array}{l}\text { Budaya Organisasi } \\
\text { (BO) }\end{array}$ & $\begin{array}{l}\text { Turnover } \\
\text { Intention (TI) }\end{array}$ & -0.211 & 0.307 & 1,797 & $\begin{array}{c}\text { Tidak } \\
\text { Signifikan }\end{array}$ \\
\hline $\begin{array}{l}\text { Organizational } \\
\text { Justice (OJ) }\end{array}$ & $\begin{array}{l}\text { Kepuasan Kerja } \\
(\mathrm{KK})\end{array}$ & 0.453 & 0.000 & 4.558 & Signifikan \\
\hline $\begin{array}{l}\text { Organizational } \\
\text { Justice (OJ) }\end{array}$ & $\begin{array}{l}\text { Turnover } \\
\text { Intention (TI) }\end{array}$ & -0.387 & 0.000 & 5.423 & Signifikan \\
\hline
\end{tabular}

Tabel 7. Hasil Mediasi Kepuasan Kerja

Sobel Test

\begin{tabular}{cccccc}
\hline Hubungan & Coefficient & Se & Z $_{\text {hitung }}$ & Sign & Keterangan \\
\hline $\mathrm{BD} \rightarrow \mathrm{KK} \rightarrow \mathrm{TI}$ & -0.080 & 0.043 & 3.327 & 0.000 & Signifikan \\
$\mathrm{OJ} \rightarrow \mathrm{KK} \rightarrow \mathrm{TI}$ & -0.101 & 0.025 & 3.879 & 0.000 & Signifikan \\
\hline
\end{tabular}

Sumber: Data primer, diolah 
Tabel 6 menunjukkan hasil pengujian $\mathrm{H} 1$ dengan nilai $\mathrm{t}_{\text {hitung }} 7.332$ lebih besar dari $\mathrm{t}_{\text {tabel }}$ 1.96, hal ini mengindikasikan adanya pengaruh signifikan budaya organisasi pada kepuasan kerja. Hasil ini menunjukkan $\mathrm{H} 1$ terdukung, artinya terdapat pengaruh budaya organisasi yang signifikan dan positif terhadap kepuasan kerja karyawan, dimana budaya organisasi yang kuat mampu meningkatkan kepuasan kerja karyawan. Karyawan merasa bahwa perusahaan menekankan untuk melakukan pekerjaan secara tepat waktu dan sesuai prosedur dalam melakukan pekerjaan. Ketepatan dan kesesuaian prosedur dalam memberikan layanan kepada tamu hotel merupakan tanggung jawab yang cukup besar dalam menjalankan pekerjaannya yang akhirnya menumbuhkan rasa kepuasaan terhadap pekerjaan yang dilakukan. Hasil penelitian ini sekaligus mendukung hasil penelitian Belias et al. (2015); Noerchoidah dan Harryono (2019) yang menunjukkan bukti adanya hubungan yang positif signifikan antara budaya organisasi dengan kepuasan kerja. Hasil penelitian ini juga memperkuat pendapat Robbin dan Judge (2019:379) bahwa faktor penting dalam mendatangkan kepuasan kerja karyawan salah satunya adalah berkaitan erat dengan aturan atau standar yang telah ditentukan oleh perusahaan. Aturan dan standar tersebut terbentuk dari budaya yang ada di dalam perusahaan itu sendiri.

Sementara itu, untuk H2 memiliki nilai $t_{\text {hitung }} 5.994$ lebih besar dari $t_{\text {tabel }} 1.96$ yang berarti kepuasan kerja berpengaruh signifikan pada turnover intention. Hasil ini menunjukkan $\mathrm{H} 2$ terdukung, artinya terdapat pengaruh signifikan dan negatif kepuasan kerja pada turnover intention. Kepuasan kerja yang didapatkan karyawan dari perusahaan, meliputi kepuasan pekerjaan yang dilakukan, mendapatkan gaji yang sesuai, kesempatan mendapatkan promosi jabatan merupakan kepuasan yang dirasakan karyawan. Dengan demikian adanya kepuasan kerja yang tinggi maka karyawan tidak akan berfikir untuk melakukan turnover intention ke perusahaan lain. Hubungan negatif antara kepuasan kerja dengan turnover intention menunjukkan bahwa semakin meningkat kepuasan kerja karyawan hotel maka turnover intention makin menurun. Sebaliknya jika kepuasaan kerja karyawan rendah maka turnover intention karyawan cenderung menjadi lebih tinggi. Hasil penelitian ini memperkuat penelitian dari Park dan Kim (2009); Abela dan Debono (2019); Emami, Moradi, Idrus, dan Almutairi (2012). Hasil penelitian ini mendukung pendapat Robbin dan Judge (2019:52) yang menyatakan ketidakpuasan karyawan diungkapkan melalui perilaku yang mengarah pada meninggalkan organisasi.

Selanjutnya, pada hasil pengujian untuk $\mathrm{H} 3$ di peroleh nilai thitung 1.797 lebih kecil dari $t_{\text {tabel }} 1.96$ yang bermakna bahwa budaya organisasi tidak berpengaruh signifikan pada turnover intention. Hasil ini menunjukkan bahwa $\mathrm{H} 3$ tidak terdukung, artinya tidak terdapat pengaruh signifikan dan negative budaya organisasi pada turnover intention. Hal ini dapat dijelaskan berdasarkan hasil jawaban karyawan bahwa beberapa keputusan perusahaan tidak sesuai dengan keinginan karyawan sehingga karyawan belum memberikan dukungan sepenuhnya terhadap perubahan peraturan yang ada di perusahaan. Selanjutnya, sebagian besar karyawan masih memiliki masa kerja 1-2 tahun yang belum terlalu lama sehingga belum benar-benar dapat menyesuaikan diri dengan budaya di dalam perusahaan sehingga masih sering membayangkan bagaimana jika mereka bekerja pada perusahaan lain. Dengan demikian, bahwa budaya organisasi memiliki pengaruh yang lemah untuk secara langsung menghasilkan turnover intention yang rendah. Hasil penelitian ini mendukung penelitian Tumbelaka et al. (2016) bahwa budaya organisasi terbukti tidak signifikan dan negatif secara langsung mempengaruhi turnover intention. Namun, hasil penelitian ini tidak memperkuat penelitian dari Jacobs dan Roodt (2011); Yeun dan Han (2016); Bosomtwe dan Obeng (2018)yang menemukan bukti bahwa budaya organisasi berpengaruh signifikan dan negatif secara langsung terhadap turnover intention karyawan. Begitu pula hasil penelitian ini tidak memperkuat hasil penelitian Dwivedi, Kaushik, dan Luxmi (2013) yang menemukan bukti adanya pengaruh signifikan dan positif antara budaya organisasi dan turnover intention. 
Perbedaan hasil penelitian ini dapat dikarenakan perbedaan aspek budaya memiliki perbedaan pengaruh hasil pada organisasi (MacIntosh dan Doherty, 2010).

Demikian juga dengan H4 menguji pengaruh organizational justice pada kepuasan kerja ditemukan nilai $t_{\text {hitung }} 4.558$ lebih besar dari $t_{\text {tabel }} 1.96$, hal ini menunjukkan organizational justice berpengaruh signifikan dan positif padakepuasan kerja. Hasil analisis menunjukkan bahwa hipotesis ini terdukung, artinya organizational justice (distributive justice, procedural justice, dan interactional justice) yang dirasakan karyawan hotel pada level yang tinggi sehingga karyawan merasa diperhatikan perusahaan maka berdampak pada kepuasan kerja. Karyawan hotel yang merasakan organizational justice di tempat kerja menganggap bahwa mereka dihargai oleh perusahaan dan diperlakukan sebagai mitra kerja akan mempengaruhi sikap dan perilaku kerja yang bisa menimbulkan rasa kepuasan karyawan. Hal ini sesuai dengan social exchange yaitu adanya pertukaran hak dan kewajiban antara karyawan dan perusahaan yang didasarkan pada equity theory. Hasil penelitan ini memperkuat penelitian sebelumnya yang dilakukan oleh Al-Zu'bi (2010); Nadiri dan Tanova (2010); Imran (2015); Suifan, Diab, dan Abdallah (2017); Suifan (2019).

Hasil analisis yang diperoleh H5 memiliki nilai thitung 5.423 lebih besar dari $t_{\text {tabel }} 1.96$ yang bermakna bahwa organizational justice ber pengaruh signifikan dan negatif pada turnover intention. Hasil ini menunjukkan H5 terdukung, artinya karyawan merasakan organizational justice telah dilaksanakan dengan baik oleh perusahaan maka keinginan karyawan untuk turnover intention ke perusahaan lain rendah. Hasil penelitian ini mendukung penelitian sebelumnya oleh Nadiri dan Tanova (2010); Suifan, Diab, dan Abdallah (2017); Arif (2018).

Hasil temuan pengujian H6 yang menguji budaya organisasi pada turnover intention melalui kepuasan kerja, terlihat nilai $Z_{\text {hitung }} 3.327$ lebih besar dari $t_{\text {tabel }} 1.96$ ) artinya budaya organisasi pada turnover intention melalui kepuasan kerja berpengaruh signifikan dan negatif. Dengan demikian H6 terdukung. Pada pengaruh secara langsung ditemukan bahwa budaya organisasi tidak signifikan dan negatif mempengaruhi turnover intention, namun dengan pengaruh tidak langsung adalah signifikan. Hal ini menunjukkan bahwa kepuasan kerja sebagai full mediation pada pengaruh budaya organisasi terhadap turnover intention. Hasil penelitian ini mendukung penelitian Park dan Kim (2009); MacIntosh dan Doherty (2010).

Sementara itu, hasil pengujian $\mathrm{H} 7$ menunjukkan nilai $Z_{\text {hitung }} 3.879$ lebih besar dari $t_{\text {tabel }}$ $>1.96$ hal ini menunjukkan adanya pengaruh signifikan dan negatif antara organizational justice dan turnover intention melalui kepuasan kerja. Hasil ini menunjukkan $\mathrm{H} 7$ terdukung, artinya organizational justice yang dirasakan karyawan hotel sangat kuat, maka akan dapat menurunkan turnover intention karyawan secara tidak langsung melalui kepuasan kerja. Hasil analisis menunjukkan bahwa kepuasan kerja sebagai partial mediation antara organizational justice terhadap turnover intention karyawan. Hal ini berarti adanya turnover intention yang tinggi tidak hanya disebabkan organizational justice yang rendah namun juga pada rendahnya kepuasan kerja yang dirasakan karyawan. Hasil penelitian ini mendukung penelitian (Suifan et al. 2017; Kuntardina, 2017).

Model penelitian ini didukung oleh social exchange theory sebagai perspektif untuk memahami perilaku karyawan di tempat kerja. Perspektif perilaku sosial melibatkan hubungan timbal balik antara dua pihak yaitu karyawan dan lingkungannya. Dalam hubungan pertukaran yang dilakukan dengan pihak lain karena mengharapkan imbalan dari pertukaran tersebut (Blau, 1964).

\section{SIMPULAN}

Berdasarkan hasil analisis dan pembahasan dapat diambil kesimpulan bahwa terdapat pengaruh signifikan dan positif antara budaya organisasi terhadap kepuasan kerja. Kepuasan 
kerja berpengaruh signifikan dan negatif pada turnover intention. Budaya organisasi tidak signifikan mempengaruhi turnover intention. Organizational justice berpengaruh signifikan dan positif terhadap kepuasan kerja. Organizational justice berpengaruh signifikan dan negatif terhadap turnover intention karyawan. Kepuasan kerja signifikan memediasi hubungan antara budaya organisasi dan turnover intention karyawan. Kepuasan kerja signifikan dan negatif memediasi hubungan antara organizational justice dan turnover intention karyawan. Dengan demikian hasil penelitian ini mendukung social exchange theory.

Berdasarkan pada hasil temuan penelitian yang ada, ditemukan adanya beberapa keterbatasan, seperti penelitian ini menggunakan sampel yang terbatas dari Surabaya sehingga tidak dapat mewakili area lain. Pada penelitian selanjutnya agar menggunakan sampel beragam dengan mempertimbangkan lokasi penelitian dan perusahaan yang berbeda kemungkinan akan mendapatkan hasil yang berbeda.Data penelitian ini diambil pada waktu sebelum terjadi pandemi COVID-19. Penelitian selanjutnya dapat dilakukan pada waktu pandemi COVID-19 sebagai pembanding hasil penelitian. Pengumpulan data pada penelitian ini menggunakan pendekatan cross sectional sehingga dalam pengambilan kesimpulan hubungan kausalitas antar variabel harus dilakukan secara hati-hati. Penelitian selanjutnya sebaiknya dilakukan secara longitudinal sehingga pengujian hubungan kausalitas antar variabel dapat mendapatkan hasil yang lebih baik.

Penelitian ini hanya mengkaji organizational justice pada 3 dimensi saja, yaitu distributive justice, procedural justice, dan interactional justice. Oleh karena itu untuk penelitian selanjutnya dapat melanjutkan dengan dimensi lainnya, yaitu temporal justice, dan spatial justice yang belum diteliti dalam penelitian ini.

\section{REFERENSI}

Abdullah, R., \& Musa, M. (2011). The study of employee satisfaction and its effects towards loyalty in hotel industry in Klang Valley, Malaysia. IInternational Journal of Business and Social Science, 2(3), 147-155. Retrieved from http://www.ijbssnet.com/journals/Vol._2_No._3_[Special_Issue_January_2011]/17.pdf

Abekah-Nkrumah, G., \& Atinga, R. A. (2013). Exploring the link between organisational justice and job satisfaction and performance in Ghanaian hospitals: Do demographic factors play a mediating role? International Journal of Workplace Health Management, 6(3), 189-204. https://doi.org/10.1108/IJWHM-04-2011-0011

Abela, F., \& Debono, M. (2019). The Relationship Between Psychological Contract Breach and Job-Related Attitudes Within a Manufacturing Plant. SAGE Open, 9(1). https://doi.org/10.1177/2158244018822179

Adams, J. S. (1965). Inequity in social exchange. Behavioral Research Service General Electric Company Crotonville, New York.

Arif, S. (2018). Impact of Organizational Justice on Turnover Intentions: Moderating role of Job Embededdness. SEISENSE Journal of Management, 1(2), 1-19. https://doi.org/10.5281/zenodo

Barakat, S. R., Isabella, G., \& Boaventura, João Maurício Gama Mazzon, A. J. (2016). The influence of corporate social responsibility on employee satisfaction. Management Decision, 54(9), 2325-2339. https://doi.org/https://doi.org/10.1108/MD-05-2016-0308

Belias, D., Koustelios, A., Vairaktarakis, G., \& Sdrolias, L. (2015). Organizational Culture and Job Satisfaction of Greek Banking Institutions. Procedia - Social and Behavioral Sciences, 175, 314-323. https://doi.org/10.1016/j.sbspro.2015.01.1206

Bernerth, J., \& Walker, H. J. (2012). Reexamining the Workplace Justice to Outcome Relationship: Does Frame of Reference Matter? Journal of Management Studies, 49(5), 
945-969. https://doi.org/10.1111/j.1467-6486.2010.00977.x

Blau. (1964). Exchange and Power in Social Life.New York: Wiley.

Bosomtwe, T. E., \& Obeng, B. (2018). The Link between Organizational Culture and Turnover Intention among Employees in Ghana. International Journal of Contemporary Research and Review, 9(08), 20951-20958. https://doi.org/10.15520/ijcrr/2018/9/08/566

Cui, X., \& Hu, J. (2012). A Literature Review on Organization Culture and Corporate Performance. International Journal of Business Administration, 3(2), 28-37. https://doi.org/10.5430/ijba.v3n2p28

Dess, G. G., \& Shaw, J. D. (2001). Voluntary turnover, social capital, and organizational performance. Academy of Management Review, 26(3), 446-456. https://doi.org/10.5465/AMR.2001.4845830

Dwivedi, S., Kaushik, S., \& Luxmi. (2013). Impact of Organizational Culture on Turnover Intentions in BPO Sector in India. Indian Journal of Industrial Relations, 48(4), 679-691. https://doi.org/http://www.jstor.org/stable/23509823

Egan, T. M., Yang, B., \& Bartlett, K. R. (2004). The Effects of Organizational Learning Culture and Job Satisfaction on Motivation to Transfer Learning and Turnover Intention, 15(3), 279-301. https://doi.org/10.1002/hrdq.1104

Emami, R., Moradi, E., Idrus, D., \& Almutairi, D. O. (2012). Investigating the Relationship between Organizational Learning Culture, Job Satisfaction and Turnover Intention in it SMEs, 12(April), 8-23. Retrieved from https://www.academia.edu/1538753/Investigating_the_Relationship_between_Organizat ional_Learning_Culture_Job_Satisfaction_and_Turnover_Intention_in_it_SMEs

Foley. (1996). US Lodging Industry: The Next Ten Years. Presentation at the Long Range Planning Committee Meeting of the Educational Institute of the American Hotel and Motel Association.

Ghozali, I. (2014). Structural Equation Modeling, Metode Alternatif dengan Partial Least Square (PLS) (4th ed.). Semarang: Badan Penerbit Universitas Diponegoro.

Hasan Ali Al-Zu'bi. (2010). A Study of Relationship between Organizational Justice and Job Satisfaction. International Journal of Business and Management, 5(12), 102-109. https://doi.org/10.5539/ijbm.v5n12p102

Henry Syauta, J., Afnan Troena, E., \& Setiawan, M. (2012). The Influence of Organizational Culture, Organizational Commitment to Job Satisfaction and Employee Performance (Study at Municipal Waterworks of Jayapura, Papua Indonesia). International Journal of Business and Management Invention ISSN (Online, 1(1), 2319-8028. Retrieved from www.ijbmi.org

Idiegbeyan-Ose, J., Opeke, R., Nwokeoma, N. M., \& Osinulu, I. (2018). Influence of organisational culture on turnover intention of library staff in Private University Libraries, South-West Nigeria. Academy of Strategic Management Journal, 17(4), 1-13.

Imran, R. (2015). Impact of Organizational Justice, Job Security and Job satisfaction on Organizational Productivity. Journal of Economics, Business and Management, 3(9). https://doi.org/10.7763/joebm.2015.v3.295

Jacobs, E. J., \& Roodt, G. (2011). The mediating effect of knowledge sharing between organisational culture and turnover intentions of professional nurses. SA Journal of Information Management, 13(1), 1-6. https://doi.org/10.4102/sajim.v13i1.425

Karkoulian, S., Assaker, G., \& Hallak, R. (2016). An empirical study of 360-degree feedback, organizational justice, and firm sustainability. Journal of Business Research, 69(5), 18621867. https://doi.org/10.1016/j.jbusres.2015.10.070

Kaur Sahi Mahajan. (2014). Employees Of Organisational Commitment and Teh Impact On 
Turnover Intentions. Asia Pacific Journal Marketing Logistics, 26(4), 621-646. https://doi.org/https://doi.org/10.1108/APJML-01-2014-0015

Kessler, L. L. (2014). The Effect of Organizational Culture on It Employees Turnover. Annals of the University of Oradea: Economic Science, 23(1), 1019-1027. Retrieved from https://doaj.org/article/f45c285185f74b418334f8896ca142bf

Koslowsky, M., Weisberg, J., Yaniv, E., \& Zaitman-Speiser, I. (2012). Ease of movement and sector affiliation as moderators of the organizational and career commitment: Turnover intentions link. International Journal of Manpower, 33(7), 822-839. https://doi.org/10.1108/01437721211268348

Kuntardina, A. (2017). Nurses and Staff Turnover Intentions in Private Hospitals, 131, 98-103. https://doi.org/10.2991/icoi-17.2017.17

Kwon Choi, B., Koo Moon, H., Ko, W., \& Min Kim, K. (2014). A cross-sectional study of the relationships between organizational justices and OCB. Leadership \& Organization Development Journal, 35(6), 530-554. https://doi.org/10.1108/lodj-08-2012-0103

MacIntosh, E. W., \& Doherty, A. (2010). The influence of organizational culture on job satisfaction and intention to leave. Sport Management Review, 13, 106-117. https://doi.org/10.1016/j.smr.2009.04.006

Mansor, M., \& Tayib, M. (2010). An Empirical Examination of Organisational Culture, Job Stress and Job Satisfaction within the Indirect Tax Administration in Malaysia. International Journal of Business and Social Science, 1(1), 81-95. Retrieved from http://ssrn.com/abstract $=1713048$

Mbah, S. E., \& Ikemefuna, C. O. (2012). Job Satisfaction and Employee s' Turnover Intentions in total Nigeria plc . in Lagos State. International Journal of Humanities and Social Science, 2(14), 275-287.

Mohamed, A., Shurbagi, A., \& Zahari, I. Bin. (2012). The Relationship between Organizational Culture and Job Satisfaction in National Oil Corporation of Libya. Iternational Journal of Humanities and Applied Sciences, 1(3), 88-93.

Mok, C., \& Luk, Y. (1995). Exit interviews in hotels: making them a more powerful management tool. International Journal Hospitality Management, 14(2), 187-194. https://doi.org/https://doi.org/10.1016/0278-4319(95)00025-8

Nadiri, H., \& Tanova, C. (2010). An investigation of the role of justice in turnover intentions, job satisfaction, and organizational citizenship behavior in hospitality industry. International Journal of Hospitality Management, 29(1), 33-41. https://doi.org/10.1016/j.ijhm.2009.05.001

Noerchoidah, Eliyana, A., \& Christiananta, B. (2020). Enhanching Innovative Work Behavior in the Hospitality Industry: Empirical Research from East Java, Indonesia. International Journal of Business and Society, 21(1), 96-110. http://www.ijbs.unimas.my/images/repository/pdf/Vol21-no1-paper6.pdf.

Noerchoidah, \& Harryono, S. (2019). The Influence Analysis of Organizational Culture and Motivation of The Caddy Work Satisfaction In A. Yani Golf Surabaya. Journal of Economic, Accounting and Management Science, 1(1), 38-45. https://doi.org/http://jeams.id/index.php/jeams/article/view/4

Park, J. S., \& Kim, T. H. (2009). Do types of organizational culture matter in nurse job satisfaction and turnover intention? Leadership in Health Services, 22(1), 20-38. https://doi.org/10.1108/17511870910928001

Parker, R. J., \& Kohlmeyer, J. M. (2005). Organizational justice and turnover in public accounting firms: A research note. Accounting, Organizations and Society, 30(4), 357369. https://doi.org/10.1016/j.aos.2004.05.001

Regts, G., \& Molleman, E. (2013). To leave or not to leave: When receiving interpersonal citizenship behavior influences an employee's turnover intention. Human Relations, 
66(2), 193-218. https://doi.org/10.1177/0018726712454311

Richardson, H. A., Yang, J., Vandenberg, R. J., DeJoy, D. M., \& Wilson, M. G. (2008). Perceived organizational support's role in stressor-strain relationships. Journal of Managerial Psychology, 23(7), 789-810. https://doi.org/10.1108/02683940810896349

Robbin \& Judge. (2019). Organizational Bahavior (16th ed.). Jakarta: Salemba Empat.

Suifan, T. S., Diab, H., \& Abdallah, A. B. (2017). Does organizational justice affect turnoverintention in a developing country? The mediating role of job satisfaction and organizational commitment, 36(9), 1137-1148. https://doi.org/10.1108/JMD-02-20170048

Suifan, T. S. (2019). The Effect of Organizational Justice on Employees' Affective Commitment The Mediating Role of Job Satisfaction, 13(2). https://doi.org/10.5539/mas.v13n2p42

Tumbelaka, S. S. X., Habsji, T. Al, \& Nimran, U. (2016). Pengaruh Budaya Organisasi Terhadap Kepuasan Kerja, Komitmen organisasional dan Intention to Leave (Studi pada Karyawan PT.Bitung Mina Utama). Jurnal Bisnis Dan Manajemen, 3(1), 94-108. https://doi.org/http://jurnal.unmer.ac.id/index.php/jbm/article/view/78/19

Tzeng, H. M. (2002). The influence of nurses' working motivation and job satisfaction on intention to quit: An empirical investigation in Taiwan. International Journal of Nursing Studies, 39(8), 867-878. https://doi.org/10.1016/S0020-7489(02)00027-5

Wang, X., Liao, J., Xia, D., \& Chang, T. (2010). The impact of organizational justice on work performance: Mediating effects of organizational commitment and leader-member exchange. International Journal of Manpower, 31(6), 660-677. https://doi.org/10.1108/01437721011073364

Wijaya, A. (2019). Metode Penelitian Menggunakan SMART PLS 03.

Yean, T. F., \& Yusof, A. A. (2016). Organizational Justice: A Conceptual Discussion. Procedia Social and Behavioral Sciences, 219, 798-803. https://doi.org/10.1016/j.sbspro.2016.05.082

Yeun, Y. R., \& Han, J. W. (2016). Effect of nurses' organizational culture, workplace bullying and work burnout on turnover intention. International Journal of Bio-Science and BioTechnology, 8(1), 372-380. https://doi.org/10.14257/ijbsbt.2016.8.1.33

Zhang, Y., Lepine, J. A., Buckman, B. R., \& Wei, F. (2014). It's not fair $\cdots$ or is it? The role of justice and leadership in explaining work stressor-job performance relationships. Academy of Management Journal, 57(3), 675-697. https://doi.org/10.5465/amj.2011.1110 